\title{
GOTTORP SLOT
}

\section{Danmarks riges lås og lukke}

\author{
Af Poul Kürstein.
}

Navnet Gottorp møder os f $\varnothing$ rste gang i et dokument fra 1268. Og der nævnes straks Slesvig-bispens curia, gård, i Gottorp Minor, det mindre eller yngste Gottorp, og hele hans villa, landsby, Gottorp Major, det større eller ældste Gottorp og alt hans gods i Arnholt. I et ældre dokument fra 1196 nævnes et Waterberg og et Openstorp. Det sidste findes endnu som marknavn under godset Falkenberg, som netop ligger ved Arnholt $4 \mathbf{~ k m}$ nordvest for Slesvig, og også Waterberg eller Waterborg er stadig knyttet til et voldsted umiddelbart nordvest for Falkenbergs bygninger ${ }^{1}$. Det må derfor antages som sikkert, at navnet Gottorp Major hører til resterne af denne store borg, som ligger nær ved hærvejen. Lyrskov hede ligger $\mathrm{i}$ det nærmeste nabolag. Efter påskeslaget 1848 lejrede den danske hær sig for natten $i$ kanonskuds afstand fra fjenden, der ikke vovede at angribe den i den stærke stilling mellem Arnholt $s \varnothing$ og Isted $s \varnothing$ og Langs $\varnothing \mathrm{en}$. I 1850 lå Falkenberg i centrum af Istedslaget, der strakte sig fra Vedelbækken i $\emptyset$ st til Trene i vest. Deraf skulle Gammel-Gottorps vigtige strategiske stilling let kunne ses. Borgens betydning var vel en så stor høvding som Slesvig-bispen værdig.

Det må være denne borg, der var åstedet for Niels Rasses $\emptyset$ ns fald 1161. Derom fortæller Sakse: En mand ved navn Niels Rasses $\emptyset$ n, som nys var udnævnt til kongens ombudsmand i Slesvig, lå i voldsom strid med biskop Esbern. dér i byen. Han gjorde et dumdristigt tog mod en af bispens navnkundigste borge og brød et ypperligt »hus « ned. Netop som han var ved at læsse det på vogne, blev han dræbt af Esberns mænd, der sqgte at hindre ham $i$ at $f \varnothing r e$ det bort. Det var Esbern bange for ville svie til ham, og han undveg hævnen ved at drage udenlands ${ }^{2}$. 


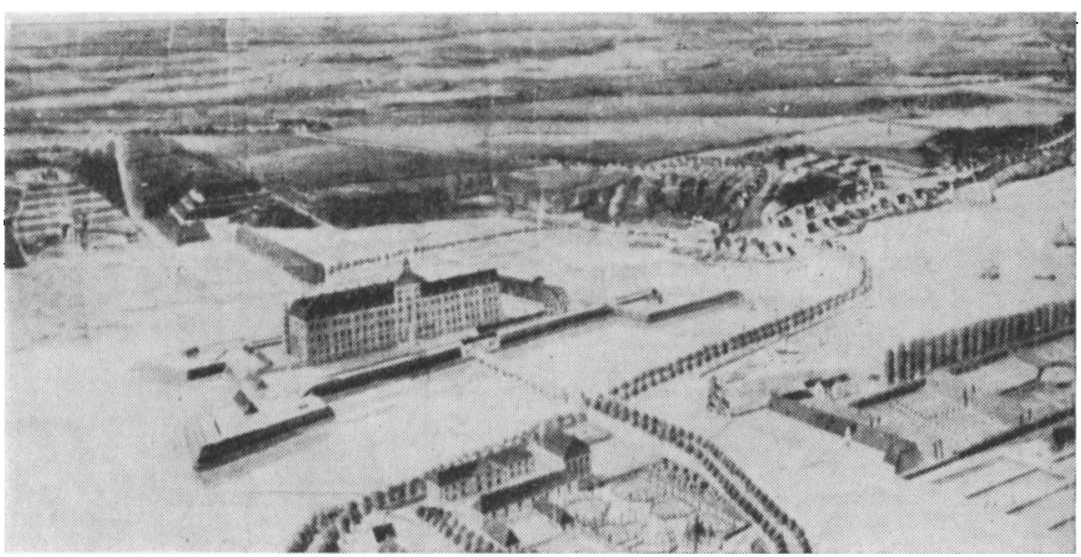

Perspektivisk fremstilling af det kongelige Slot Gottorp. 1732. Farvelagt tegning af overkonduktфr Hans Christoph Lønborg1s. Gengivet med venlig tilladelse af hertugen af Slesvig-Ilolsten, Lyksborg. Billedet viser Gottorp pd dets højdepunkt med bastioner og giver et udmerliet indtryk af den rolle, $v$ a ndet spillede, f $\phi r$ bastionerne blev sløjfet, gravene delvis fyldt eller groet til, og dxmningen gjort bredere. I forgrunden $v$. Dernaths palæ (Bjelkes palæ), i baggrunden slotsparken med Neuwerk (Nyvark). Sammenlign dette billede med omslaget til Sфnderjyske årbøger 1958, II.

Af samme grund har kongen, Knud Valdemarss $\phi$ n (den 6.) vel inddraget borgen, for det nævnte dokument fra 1196 fortæller netop om kongens retshandel med gård og gods. Senere må det dog være kommet til bispen igen.

Stednavnet er dansk, sammensat af mandsnavnet Goti og efterleddet thorp. Under normale forhold skulle det udvikles til trup. Der findes da også former som Gotterup, Gottrup og Guttrup. August Sach har endda fundet formen Gammel Guderup, som man skulle vente som den lydrette, endelige form. Imidlertid er den gamle oprindelige form Gottorp tidligt overf $\phi r t$ til det nye Gottorp. Ved hyppig brug i danske, latinske og plattyske kilder er formen Gottorp. blevet fæstnet. Formen Gottorf er sproghistorisk vrang, uden synderlig ælde og b $\phi \mathbf{r}$ skyes $^{3}$.

Det nye Gottorp blev bygget af bispen på en $\emptyset$ i Sliens inderste vig mellem 1161 og 1268 , når vides íkke. Dér lå det om muligt endnu bedre end det gamle, og hertug Erik Abelsøn kastede snart sine фjne på det stærke slot. Slot betyder jo egentlig fæstning, og omgivet af vand og side enge på alle sider var Gottorp en 
méget stærk fæstning. I slaget på Lo hede i 1261, mellem hertugen og de holstenske grevers hær mod den danske, som blev fulgt af selve dronningen, Margrete Sprænghest, blev biskop Niels, der var i den danske hær, taget til fange af hertugen. Denne, som hidtil havde holdt til på St. Jørgensborg på Mågeøen i Slien, tvang ham til et mageskifte, hvorved Gottorp kom i hertugens hånd. Det blev bekræftet af biskop Bonde $\mathrm{i} 1268$ ved det ovenfor omtalte dokument 4 .

På dette tidspunkt havde Danevirke tabt sin værdi som landeværn. Fra nu af drejer krigskunsten sig om faste punkter, fæstninger, slotte. Gottorp bliver Danevirkes direkte arvtager. Middelalderen udtrykte klart Gottorps styrke, når klagesangen fra 1329 siger:

\section{Guttrup castrum optimum \\ Danorum præsidium \\ Gottorp f $\phi r$ din sikre vold \\ Danmarks Riges bedste skjold}

(E. v. d. Recke $)^{\mathrm{5}}$

Rydårbogen udtrykker sig endnu kraftigere. Gottorp er »quasi clavis et custodia totius Daniae«, »ligesom hele Danmarks lås og lukke«.

Da de sønderjyske hertuger imidlertid snart kom i ledtog med de holstenske grever, ja, til sidst endte aldeles i deres ledebånd, kom låsen $\mathrm{i}$ de holstenske grevers vold, og de vidste udmærket godt, hvor vigtig og hvor stark borgen var. Det fik de danske at mærke i 1329, da stærke jyske skarer indtog Haderslevhus og stødte frem til Gottorp. De led et frygteligt nederlag på Hestebjerget på samme sted, hvor Kristoffer 2 . få år $\mathbf{i}$ forvejen havde måttet nemme den samme lære.

Som pantherre sikrede greverne sig, at Gottorp af alle pantsatte borge skulle indløses sidst, og da Margrete Valdemarsdatter endelig stod med pengene $i$ hånden, nægtede de pure at tage imod løsesummen og åbne borgen. Da den kloge kvinde ikke kom længere med lempe, provede hun med list. Enkehertuginde Elisabeth anede dog hendes' hensigt, og ved Margretes bes $\not g$ på slottet, hvortil en overrumpling var planlagt, var tårnet fuldt af 
bueskytter, så også hun måtte give op. Straks efter, i 1412, døde hun.

Det blev hendes fosters $\varnothing$, Erik af Pommern, der måtte prøve våbenlykken. I 1415 havde han det meste af hertugdømmet inde. Han manglede kun porten: Gottorp. Med omtanke skred han frem med anlæg af borge på alle vigtige punkter. I passet ved Farensted byggede han Vedelspang. Mod friserne byggede han Friserborgen i vest. Svavsted blev styrket. Vigtigst af alt var en kade af støttepunker langs Sliens l $\phi b$, ved Lindå over for Stubbe, bispeborgen, der også var $\mathrm{i}$ kongens hånd, og Kongsborg ved Mysunde. Svaneborg over for Arnæs må også efter sit anlæg høre denne tid til.

Efter disse omhyggelige forberedelser og efter Femerns indtagelse kunne kongen i 1416 angribe Slesvig og Gottorp fra Hestebjerget og Mågeøen. Et usædvanligt lavvande af den slags, som kan indtræde i Slesvig ved vedvarende vind fra sydvest, og ikke som den holstenske krønikeskriver mener, at »himlens herre tilstod holstenerne med heste at gå på vandet og nå фen J $\varnothing$ rgensborg (Mågeøen) og de danske skibe«, har sikkert været årsagen til det uventede holstenske anfald, som tilføjede kongen så alvorlige tab, at belejringen måtte hæves.

Men i 1417 kom han igen med en flåde på 2000 skibe til Slesvig. Få dage efter overgav byen sig, og alle regnede med, at Gottorp snart ville falde, dårligt forsynet med f $\phi$ devarer som borgen var. Holstenerne fik imidlertid hjælp fra Hamborg. At det var muligt, skyldes naturforholdene, som hindrede en fuldstændig indeslutning. Det endte med, at kongen tabte alt, hvad han havde vundet.

Udholdende $\mathrm{i}$ sin vilje til at fri Sønderjylland kom kongen igen for tredje gang, med stor hærmagt og en kanon! i 1426. Mellem byen og Gottorp opkastede han en firkantet skanse på Hestebjerget. Den havde »dobbelt ovenud dybe grave og var omgivet med lange pæle«. Holstenerne kaldte den »Hatesborch $\ll$ og danskerne Avindsborg «. Enden blev som sædvanlig. Efter en våbenstilstand overfaldt holstenerne borgen, tog den og huggede mandskabet ned. Resterne af Avindsborg ligger endnu på Skytte- 
kobbelen på Hestebjerget som et minde om en konge, hvis vilje bør påsk $\varnothing$ nnes. Men låsen lod sig ikke sprænge ${ }^{\natural}$.

Først Christian 1. fik nøglen til Gottorp ved forliget i 1460 . I over hundrede år havde borgen været på holstenernes hænder og værnet deres vælde i S $\phi$ nderjylland. Det fik varige f $\varnothing l$ lger.

Hertugd $\varnothing$ mmernes evige udelelighed varede kun 30 år. Ved S $\varnothing$ nderjyllands f $\varnothing$ rste deling i 1490 kom slottet til Frederik. Under ham var slottet arnested for rænker mod Christian 2., og her mødtes prælater, ridderskab og adel den 14 . april 1523 for at opsige ham huldskab og troskab og hylde Frederik 1.

Frederik 1. blev boende på Gottorp, og derfor blev slottet det virkelige regeringssæde for Danmark, Slesvig, Norge og Holsten. Frederik døde i 1533, men Gottorp var rigernes midtpunkt lige til 1539.

I Frederik 1.s og Christian 3.s tid blev der bygget meget på Gottorp. Om slottets ældste bygninger vides såre lidt. Der har været et stort tårn i øst. Hertug Valdemar 4. genopbyggede hovedbygningen i 1295 . Man mener, at dens mure skjuler sig $i$ den nuværende vestfløj. Den brændte i 1492 , men blev genopf $\varnothing \mathrm{rt}$ af Frederik. I 1530 lod hans lensmand i Bergen Apostelkirken nedbryde, fordi den lå $\mathrm{i}$ vejen for Bergenhus' kanoner. Stenene blev f $\phi r t$ til Gottorp. De blev brugt til at opf $\phi$ re de ældste dele af sydfløjen. Det er kældrene og den lange hvælvede sal, hvor Landsmuseet udstiller middelalderens kirkekunst. Også det store, runde tårn på ydersiden af nordvesthjørnet må efter sin hele fremtoning høre til i denne tid. Også under Christian 3. ved vi, at der blev arbejdet ivrigt på at styrke forsvaret, uden at vi dog kender enkeltheder ved udenværkerne. Det var nødvendigt, for krigsfare truede fra kejseren og Christian 2.s slægt?

Ved Sønderjyllands anden deling i 1544 tilfaldt Gottorp kongens broder, hertug Adolf. Hans slægt havde slottet inde til 1713 (1721). Den kaldes derfor Gottorperne. Nytårsaften 1564 gik det hedt til, for da brændte det $\phi$ stre hus, som vi ellers ikke ved noget om. Han genopbyggede den $\phi$ stre fl $\phi j$ og byggede nordfløjen af nyt, sådan som de to fløje står i dag, 1565-68. Han anlagde også 3 stærke bastioner uden om slottet 1573. Den fjerde, i nordvest, blev anlagt af hertug Frederik 3. i 1626.1582 an- 


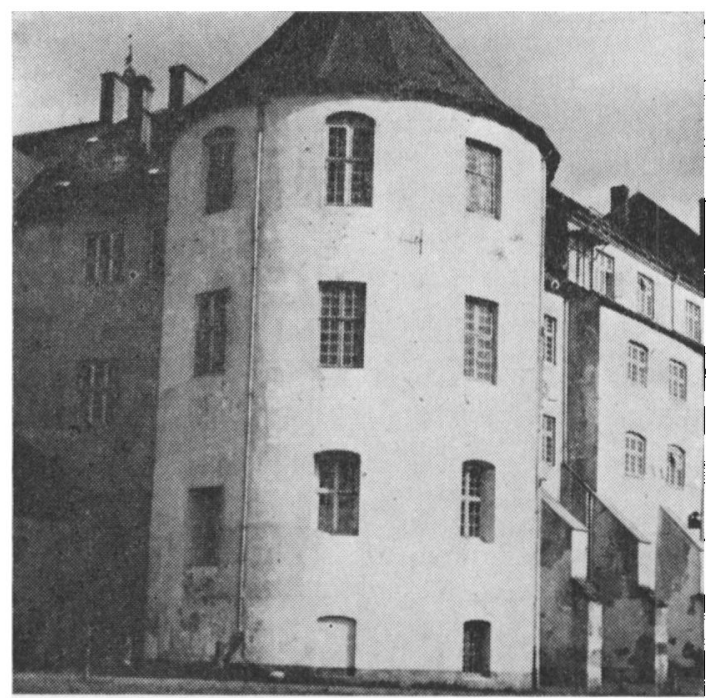

Det kraftige, runde tarn, hoor vestfløjen modes med nordflijen.

lagde Adolf den store Sli-dæmning, som i dag bærer hovedvejen. Dengang gik færdselen vest om byen og slottet på Hæivejon, så hensigten med dæmningen har snarest været at sikre, at roldgravene ikke blev tørre ved lavvande. Det ses af det følgende:

I Kejserkrigen åbnede hertugen slottet for en kejserlig besætning i 1629. Christian 4. angreb imidlertid fjenden ved et knibtangsangreb, idet han samtidig kastede tropper $i$ land på vest-

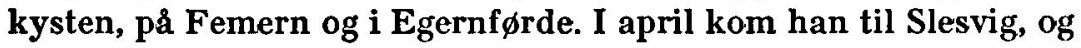
fra Hestebjerget åbnede han belejringen med svært artilleri og meget fodfolk. Han vovede sig endog langs med dæmningen for at se, om den kunne undermineres. Hensigten må have været at sænke vandstanden i gravene. Freden i Lybæk afværgede den fastsatte storm.

Det var sidste gang, at den prøvede fæstning blev virkeligt forsvaret. Trods arbejder på værkerne i $1651 \mathrm{og} 1665$ blev slottet ikke forsvaret mod brandenborgerne og polakkerne i 1657-58, og i Store Nordiske Krig måtte det i 1700 og igen i 1713 overgives til Frederik 4. Tønning var nu blevet hertugens hovedfæstning. Med dens fald var hertugens magt i Slesvig og dermed Gottorps storhedstid forbi ${ }^{8}$. 
Gottorpernes stræb efter magt og ære fandt mod enden sit udtryk $i$ en vældig sydfløj, der $i$ vest hævede sig over Frederik 1.s beskedne hus og i $\emptyset$ st var ny fra grunden af. I den, som $i$ nordvesttårnet, sidder der sten fra Valdemarsmuren, som den gottorpske generalmajor Zacharias Wolff havde set i fuld højde så sent som i 1696, men siden da kun fjæler sig i voldens udskredne fyldjord`. Også i denne bogstavelige forstand er Gottorp arvtager i Danevirkes bo. Sydfløjen blev færdig i 1703. Siden er intet nyt bygget på selve slottet.

Da Frederik 4. endelig kunne indlemme det gottorpske Slesvig i kronen, måtte arvehyldningen med f $\varnothing$ lgestrenghed ske på Gottorp. Den fandt sted i slotskirken. Dette rum er det eneste som i udstyr er bevaret i hovedtræk urørt af hertug Adolfs renæssanceslot. I dens fyrstestol eller bedekammer sad efter gottorperne Kgl. Majestæts statholder i hertugd $\varnothing$ mmerne, fra 1768 landgrev Carl af Hessen. I hans tid blev kronprins Frederik (6.) viet til hans datter Marie i slotskirken. En anden, Louise Caroline, blev viet til prins Vilhelm, senere hertug af Lyksborg. Ved ham blev hun mor til en konge, Christian 9., som fødtes på Gottorp 1818 og blev døbt i slotskirken. Landgrev Carls s $\phi$ n Frederik, som blev statholder 1836, blev 7 år gammel chef for Slesvigske Infanteriregiment, nu i Haderslev. Det ene af de to vagthuse foran slottet er bygget til dette regiment, det andet til livregiment dragoner ${ }^{10}$. Han afløstes i 1842 af prins Frederik af $\mathrm{N} \phi \mathbf{r}$, som sløjfede de 3 bastioner. Deres jordmasser blev væltet ud $i$ graven, så at slotsøen blev st $\varnothing$ rre. Bastionernes sten ligger $i$ dag som kantsten i Lollfuss. Een kom dog på museum, fordi den var en runesten, Gottorp-stenen eller Haddeby 4. Den er nu havnet $i$ en af slottets fornemste sale. I denne periode var der provinsregering med overret og konsistorium og juridisk og teologisk embedseksamen på Gottorp.

Det slesvigholstenske oprør i 1848 blev et vendepunkt i slottets historie. I dispositionen for Slesvig-slaget var garden kommanderet til at forsvare slottet. Den trak sig dog for tidligt vak. En overgang sad slesvigholstenernes regering på slottet, der samtidig var lazaret. Efter krigen blev slottet kaserne. Frederik 1.s hvalvede hal, hvor i det 17. århundrede det berømte gottorpske 
bibliotek var anbragt, blev sovestuer for 96 mand. Dronning Sofies stue i den smukke karnap blev folkestue for marketenderen. Karnappen blev фdelagt ved en eksplosion i 1871. Der blev bygget stalde, ridehus ( $\mathrm{nu}$ nedrevet) og eksercerhus. Det huser nu Nydam-båden og Thorsbjerg-krigernes våben. $\mathrm{Og}$ nu var det garnisonens ældste officerer, der sad i hertugens bedekammer ${ }^{11}$.

Det vedblev det at være efter 1864, for også prøjserne brugte slottet som kaserne lige til 1945. Først i deres tid er de berømte kaskader i slotsparken blevet фdelagt. Ved skydebanerne langs Dyrehavens bryn var der skydeskiver i danske soldaters lignelse ${ }^{12}$. I 1917 hærgedes slottet af ildsvåde. Tårnet, sydfløjens vestende og hele vestfl $\varnothing j$ jen brændte til de n $\varnothing$ gne mure. Rygtet gik $\mathbf{i}$ byen, at en utro kassemester ville dække over svind. Og i 1920 oplevede slottet sin sidste belejring, forhåbentlig da. Derom er der gjort rede i Sønderjyske årbøger 1958.

Efter at engelske og polske tropper havde forladt slottet efter 1945, er en ny tid oprundet for den gamle fæstning, som mere end nogen anden bygning legemligg $\phi r$ S $\varnothing$ nderjyllands historie. Men den st $\varnothing$ rste fare i dets tilværelse truede. Byens st $\varnothing$ rste politiske koryfæ, en kræmmer, der blev landråd, udtalte, at han håbede at se rygende fabriksskorstene skyde op gennem Gottorps tage. Det ville være, syntes han, den skønneste krone på hans politiske livsværk. Han kom til at klare sig uden krone. Mænd af forskelligt folkeligt sind, men af samme hjerte for Slesvigs historie fik endelig sikret det gamle slot en hæderlig alderdom som hus for det Slesvigholstenske Landsmuseum og for Museet for Forhistorie. Også det Slesvigholstenske Landsarkiv er her endnu, men agter at vende tilbage til Kiel.

\section{Henvisninger:}

1) C. C. Lorenzen: Historisk-topografiske Meddelelser om Gottorp Slot, 1875. 2) Sakses Danesaga, 1909, bd. 2, s. 58. 3) Wolf gang Laur: Die Ortsnamen in Schleswig-Holstein, 1960. 4) Om Slesvig-bispen og Gottorp se Johanne Skovgaards afsnit i: Slesvig delte Bispedømme, 1949. Om litteratur og billeder til Gammel Gottorp se endvidere: Die Kunstdenkmäler des Landeskreises Schleswig, 1957, s. 102 ff. 5) Oversattelse af klagesangen i Knud Fabricius: Fra Saxo til Povl Helgesen, 1928-30, s. 170 ff. 6) Kr. Erslev: Danmarks Historie under Dronning 
Margrethe og hendes nærmeste Efterfølgere, 1882-1901, bd. 1-2. 7) Otto Norn: Christian III's Borge, 1949, bd. 1-2. Jorenzen og efter ham Schmidt sætter tårnets opførelsesår til 1574. Jeg tvivler. 8) Robert Schmidt: Schloss Gottorp, ein nordischer Fürstensitz, 2. Ausg. 1903. Richard Haupt: Die Bau- und Kunstdenkmäler der Provinz SchleswigHolstein, 1888, bd. 2, s. 332 ff. Peter Hirschfeld: Herrenhäuser und Schlösser in Schleswig-Holstein, 2. Aufl. 1959. 9) Herbert Jankuhn: Die Wehranlagen der Wikingerzeit zwischen Schlei und Treene, 1937, s. 163. 10) Niels Friis: Slesvigske Fodregiment i Krig og Fred, 1953. 11) E. Bodenhoff: Don gamle General, 1914, s. 107. Om den danske garnisonsmenighed: E. Høyer Møller: Livs- og Krigserindringer, 1894: Th. J. Madsen: Garnisonsskolen i Slesvig By i: Sønderjyske årbøger 1946, s. 109 ff. Erik Bondo Svane: Arkitekten L. A. Winstrups vigtigste Arbejder. IX. Slotskapellet på Gottorp i: Sønderjyske årbøger 1946, s. 205 ff. 12) L. Bobé: Livsdagen lang, 1947, s. 219. 13) Weilbachs Kunstnerleksikon, bd. 2, s. 314 . 